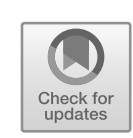

\title{
1 »Wir schenken Ihnen die Mehrwertsteuer! « Wie groß ist der gewährte Rabatt wirklich?
}

Das Ehepaar Wagner sieht sich nach neuen Wohnzimmermöbeln um. Am Einrichtungshaus prangt ein riesiges Werbebanner:

Wir schenken Ihnen die Mehrwertsteuer auf Ihren Möbelkauf!

»Das kommt uns gerade recht «, freut sich Frau Wagner, »da können wir $19 \%$ sparen. Ausgezeichnet! «

»Da steckt bestimmt ein Trick dahinter. « Herr Wagner ist skeptisch. »Die ziehen bestimmt nicht einfach $19 \%$ vom Verkaufspreis ab. Ich werde zu Hause einmal nachrechnen. «

Angenommen, ein Möbelstück kostet $P$ Euro. Dann beträgt sein Preis abzüglich der Mehrwertsteuer von $19 \%$ nur noch $P_{1}=\frac{P}{1,19}$, denn schlägt man die Mehrwertsteuer auf diesen niedrigeren Betrag wieder drauf, ergibt sich gerade $P_{1}+\frac{19}{100} \cdot P_{1}=1,19 P_{1}=P$. Will man nun den Rabatt $r$ berechnen, der hinter der Werbeaktion steckt, hat man vom Ansatz $P_{1}=P \cdot(1-r)$ auszugehen, was auf die Beziehung $P(1-r)=\frac{P}{1,19}$ und nach Kürzen mit $P$ auf $1-r=\frac{1}{1,19}$ bzw.

$$
r=1-\frac{1}{1,19}=\frac{1,19-1}{1,19}=\frac{0,19}{1,19}=0,1597=15,97 \%
$$

führt.

»Ich habe es doch gewusst «, triumphiert Herr Wagner, »ein Trick ist dabei, $19 \%$ sind es nicht, es sind nur knapp $16 \%$.«

$»$ Aber $16 \%$ sind doch auch nicht schlecht«, beschwichtigt ihn seine Gattin.

$\gg$ Ja, schon. Aber es sind keine $19 \%$, wie einem suggeriert wird «, grummelt Herr Wagner. Irgendwie ist er trotzdem unzufrieden. 